\title{
FEMINISTIESE TEOLOGIE
}

\section{INLEIDING}

Feministiese Teologie - of teologie! - (FT) vorm 'n onderdeel van wat bekend staan as bevrydingsteologie en kontekstuele teologie. FM is bevrydingstenlogie "because it is concerned with the liberation of all people to become full participants in human society"1). In besonder gaan dit natuurlik oor die bevryding van die vrou, die oudste onderdrukte wese op aarde, en veral die swart vrou, "perhaps the most oppressed of all the oppressed" ${ }^{2}$ ).

FT stry saam met die feministiese beweging teen seksisme en diskriminasie en vir emansipasie van die vrou. Dit is deel van 'n kulturele rewolusie wat gemik is op 'n totale vernuwing en herstrukturering van die samelewing op die basis van gelykheid, geregtigheil en vryheid vir alle mense. Die doel is "to commit Christians to radical political and social change, and to transform society in order to create a new and more humane world" $\left({ }^{3}\right)$.

FT kan ook omskryf word as 'n sistematiese teologiese refleksie van die wêreldwye vroulike ervaring as een van onderdrukking en diskriminasie. As sodanig is dit ook 'n vorm van kontekstuele teologie. Sonder dat vrouens nie werklik vry is nie, kan daar nie van volle vryheid sprake wees nie. "True liberation for all can come only when women are liberated" $\left({ }^{4}\right)$.

Dit is nie verrassend nie dat in die F $T$ skerp kritiek uitgespreek word teen die paternalisme en manlike oorheersing in kultuur, politiek, ekonomie, opvoeding samelewing, huwelik en godsdiens; teen 'n manlike teologie, 'n manlike kerk en ook 'n manlike God. So word daarvoor gepleit en geagiteer dat die vrou met mér te doen moet hê as "kinders, klere en kombuis", en dat sy vry moet wees om sonder voorskrif van 'n ander ('n man) haar Godgegewe talente te beoefen. Kyk ons na die wêreldgeskiedenis moet ons ook nie bloot praat van "his-story" nie maar ook van "her-story" $\left({ }^{5}\right)$.

Ons moet ook minder praat in terme van broederskap of susterskap maar veel eerder in terme van persoonskap.

' $n$ Besonder interessante verskynsel tree egter by die $F \mathrm{~T}$ as bevrydingsteologie na vore en dit is die kritiek op ' $n$ ander systroom van die bevrydingsteologie $\mathrm{nl}$. Swart Teologie. "Where are Black women in Black Theology?" vra Jacquelyn Grant en sy antwoord: "They are in fact, invisible in Black Theology" $\left({ }^{6}\right)$. Sy gaan voort "There are oppressive realities in the Black community which are related to, but independent of , the fact of racism. Sexism is one such reality - Racism and sexism are interrelated just as all forms of oppression are interrelated. Sexism, however, has a reality and significance of its own because it represents that peculiar form of oppression suffered by Black women at the hands of Black men" ( ${ }^{7}$ ). Sy konkludeer dan dat "the fact that Black Theology does not include sexism specifically as one of those injustices is all too evident. It suggests 
that the theologians do not understand sexism to be one of the oppressive realities of the Black community" $\left({ }^{8}\right)$. - Cone self het weliswaar later seksisme uitdruklik afgewys.

Die omvang van die probleem word duidelik as daaraan gedink word dat meer as $50 \%$ van die swart gemeenskap in die VSA uit vrouens bestaan terwyl die vrouens meer as $70 \%$ van die swart kerke uitmaak $\left({ }^{9}\right)$.

Die feministiese beweging, wat in die sestigerjare in die VSA ontstaan het en na Europa oorgewaai het, en in 1971-75 'n hoogtepunt bereik het met die agitasie ten gunste van aborsie ("baas in eigen buik"), is, soos ook die F T, 'n komplekse verskynsel.

So kan daar bv moeilik in die algemeen gepraat word van "die F. T". Daarvoor is daar onderling tussen die feministiese teoloë te veel verskil en nuansering. Sommige onderskei bv. tussen "harde" en "sagte" feministe (F S Edwards), terwyl ander praat van rewolusionere feministe (wat selfs die Bybel vanweë sy patriargalisme verwerp) en reformiste (wat wel die Bybel aanvaar maar hom van sy patriargalisme wil ontdaan $\left({ }^{10}\right)$.

Van die bekendste name onder die feministiese teoloë is die volgende:

- in die VSA: Mary Daly. 'n ekstreme eksponent en gewese Roomskatoliek; Rosemary Ruether, 'n Rooms-katoliek; Letty Russell, 'n Presbiteriaanse predikant.

- in Duitsland: Elizabeth Moltmann-Wendel (vrou van die bekende teoloog Jürgen Moltmann).

- in Nederland: Catharina Halkes van die Rooms-katolieke Universiteit te Nijmegen.

- van Asië: Marianne Katoppo.

- van Afrika: Amba Oduyoye (Nigerië).

- van Suid-Afrika: F. Edwards.

$\mathrm{Lg}$ is voorstaander van die sg holistiese feminisme, waar man en vrou as komplimenterend, en nie kompeterend nie tot mekaar gesien word. Bo en behalwe hierdie interpersoonlike verhouding tussen man en vrou, gaan dit ook oor die harmoniëring van die intrapersoonlike manlike en vroulike elemente in die een persoon.

\section{UITEENSETTING}

Soos alreeds uit vorige opmerkings afgelei kan word, raak die $\mathrm{F} T$ in 'n sekere sin die hele veld van die teologie. Waar ons tans daartoe oorgaan om enkele van die belangrikste beskouinge nader te ontleed, hou ons voortdurena rekening met die onderskeie nuanses en beklemtoninge wat eie is aan die F T. Lank nie almal nie hou rewolusionêre beskouinge daarop nie.

\section{Skrifleer}

Soos algemeen verwag kan word, word deur sommige met die Skrifleer bepaalde probleme ondervind. Sommige vind die Bybel onaanvaarbaar vanweë sy androsentriese simbole en patriargale konteks vgl. die 10e gebod waar die vrou saam met die diensknegte, osse en 
esels genoem word. Die Bybel word gekritiseer omdat dit teen die vrou diskrimineer, 'n patriargale sisteem kondoneer en sodoende seksisme bevorder. Daarom moet dit van sy chauvinisme ontdaan word en daarvoor is selfs 'n nuwe (feministiese) Bybelvertaling nodig. Die teologiese taal moet herkonstrueer word sodat die sprekeoor 'n manlike God vervang kan word met die oor 'n androgene (manlike en vroulike). God. Die Skrif moet dus as't ware gedesimboliseer word.

Manlike teoloë word gekritiseer omdat hulle die skeppingsleer en sondeval - en Paulus - gebruik om patriargalisme te sanksioneer, die status quo te handhaaf en vrouens op hulle plek te hou. Swart feministe kritiseer ook swart teoloë dat hulle tov. slawerny 'n nuwe hermeneutiek toepas maar nie tov. die vrou nie.

Sommige vind onder andere eerder aansluiting by Gen. 1 as by Gen. 2. In Gen. 1 word immers na die mens verwys as geskape na die beeld van God terwyl in Gen. 2 genoem word dat die vrou uit die man geskep is (11).

Onlangs is in die boek Godsdienst en incest, wat handel oor die seksuele misbruik wat vaders, broers, ooms en oupas van dogters en meisies maak, in Nederland met 'n voorkoms van $515 \%$ ( 1 uit 10 vrouens), die beskuldiging gemaak dat godsdiens en bloedskande baie nou saamhang: die Christelike geloof, met sy sterk Bybelse patriargale verhoudinge, is die direkte orsaak van bloedskande. Mans misbruik eenvoudig hulle magsposisie. Tereg wys Velema daarop dat hierdie grondstelling nie klop nie aangesien die hele Skrif hom tog baie sterk teen bloedskande uitspreek. En hoe moet dit dan verklaar word dat blo€dskande ook wyd onder nie-Christene voorkom? $\left({ }^{12}\right)$.

of 'n nuwe hermeneutiek tov die ou Bybel, ò 'n nuwe Bybel (-vertaling), of geen Bybel skyn dus nodig te wees.

'n Voorstel wat aan die hand gedoen word om die probleem te omseil, lui soos volg: God se handelinge met die mens gaan steeds voort, die Bybel is dus nie die laaste woord nie aangesien die mens God vandag opnuut onder leiding van sy Gees ervaar; God het in die volheid van die tyd sy Seun gestuur en op die regte tyd ook weer feminisme.

In hierdie verband sou ons kortliks daarop wou wys dat dit teologies uiters gevaarlik is om die Skrifgeworde Woord, waarvan die Vleesgeworde Woord Jesus Christus, die Sentrum is, ook maar enigsins te devalueer ten gunste van 'n ervarings- of Geestesteologie. Weliswaar hang al hierdie momente ten nouste met mekaar saam maar dan nooit so dat die Skrifopenbaring verdwyn nie. Verder moet ook nie oorhaastig gekonkludeer word dat die kultuurhistoriese konteks waarbinne die Godsopenbaring hom voltrek outomaties as normatief annvaar word nie. In hierdie verband sou ook 'n saak daarvoor uitgemaak kon word dat die vrouens in die Skrif veel vryer was as dié in die sekulêre wêreld en dat hierdie perspektief steeds groter uitgegroei het om in die NTe verkondiging ' $n$ hoogte- 
punt te bereik wat eintlik ongeëwenaard is (Gal. $3: 28$ ). Ook moet baie duidelik rekening gehou word met die skeppingsorde (die vrou voor die val), die sondeorde (die vrou na die val) en die verlossingsorde (die vrou in Christus).

\section{Godsleer}

Begryplik word ook die manlike, patriargale Godsbeeld van die Skrif gekritiseer, veral deur Mary Daly, wat selfs al praat van die dood van God-die-Vader. Die Bybelse Godsbeeld is te manlik-heerseragtig en die patriargale simbole moet met ander vervang word, bv moeder ipv vader, of dan ten minste met vriend. Ook die Ons Váder kom dus onder kritiek.

Sommige meen dat die groot klem op die vaderskap van God in die OT verklaar moet word as 'n reaksie teen die natuurgodsdiens van die Kanaäniete met hulle manlike (Baäl) én vroulike (Anat) gode (Ruether).

In hierdie verband sou ons daarop wou wys dat die mens, met sy beperkte verstand, eintlik altyd simbolies oor God die Majesteitlike, praat. Hy word "Vader" genoem, maar eweseer "Rots" (Ps. $19: 15 ; 89: 27$ ) of "Herder" (Ps. 23) ens. In elke konteks van menslike belewenis word $\mathrm{Hy}$ weer anders genoem. So huiwer die Skrif ook geensins om sekere "moederlike" aspekte aan God toe te skryf nie, bv. Jes $63: 7,66: 13$, Deut $32: 18$. (Opvallend ook is dat die Hebreeuse woord vir Gees, nl ruach, vroulik is). Daar is dus geen rele om die Bybel oor to skryf of die Godsbeeld te verander nie. God is so groot in sy wese en so ryk in sy genade dat Hy onmoontlik in een beeld vasgevang kan word. Hy is wat $\mathrm{Hy}$ is! Hy is in Christus die Heiland. Hy is deur sy Gees die Vernuwer.

\section{Sondeleer}

Sonde word veral gesien as onderdrukking (van die vrou), as patriargalisme. Sonde is nie net persónnlike sonde nie maar ook strukturele sonde. "The individualistic concept of sin ignores this socialcosmic dimension of evil" (13). Sonde bou korporatiewe strukture van vervreemding en onderdrukking wat mans individueel nie kan oorkom nie. 'n Privatiserende konsep van sonde is onhoudbaar.

Hierop sou ons wou antwoord dat sonde inderdaad 'n strukturele kant besit wat nie ontken kan word nie. Tog moet voortdurend daarteen gewaak word om dit van sy relasionele aspek (tov God) te ontdaan.

\section{Christologie}

Soos in die Godsleer word daar ook in die Christologie deur sommige feministe skerp kritiek uitgespreek, veral teen die manlike Christus (Mary Daly). Ons moet ook eerder van Jesa Christa praat. Mary Daly wil verbybeweeg by wat sy Christolatrie noem na die "Second Coming of Women". Besondere aandag word ook aan die omvattende verlossing deur Christus bestee: verlossing deur Christus omvat nie net individueel-geestelike verlossing nie maar ook politieke en sosiale. 
Uok hierdie benadering, as reaksie teen 'n piëtistiese versmalde verlossingsboodskap, moet positief waardeer word, solank daarteen gewaak word dat die evangelie nie weer na die ander kant (slegs politieke verlossing) versmal word nie, asook teen 'n sunergisme waar die mens saam met Christus medeverlosser word. Iets anders is dit om te aanvaar dat die evangelie bepaalde konsekwensies vir 'n (regverdige) samelewing inhou en dat die mens diensbaar moet wees aan die koninkryk van God en sy geregtigheid.

Verder, waarom sou dit vernederend wees vir 'n vrou om deur 'n Man - Seun van God - gered te word? Is dit nie al klaar 'n vernedering om as mens gered te word nie? Met die hele debat rondom 'n sg manlike of vroulike Verlosser word die sáák waaroor dit gaan verbygekyk en so kan maklik die verlossingsboodskap self misgeloop word.

\section{Ekklesiologie}

Veral in die leer oor die kerk word van die skerpste kritiek van die F T sigbaar, omdat juis in die kerk die diskriminasie teen die vrou besonder duidelik aan die lig tree. In talle kerkgroeperinge mag sy nie stem of praat nie, mag sy nie in die besondere dienste staan nie en nie op kerkvergaderinge haar bydrae lewer nie. Haar bydrae in die kerk word beperk tot swye kosmaak en kinders oppas.

Vandaar Jacquelyn Grant se opmerking: "If the liberation of women is not proclaimed, the church's proclamation cannot be about divine liberation. If the church does not share in the liberation struggle of Black women, its liberation struggle is not authentic" (14). "It is only when Black women and men share jointly the leadership in theology and in the church and community that the Black nation will become strong and liberated" $\left({ }^{15}\right)$. Uiteraard raak hierdie godsdienstige emansipasie van die vrou álle aspekte van die kerklike lewe, tot in die liturgie.

Ons kom later op hierdie aspek - kerk en vrou - breedvoeriger terug. Interessant is dit om reeds hier op te merk dat die beeld van bruidsgemeente, met Christus as die Bruidegom, veelvuldig in die Skrif voorkom (die Griekse woord vir kerk/gemeente nl ekklesia, is ook vroulik).

\section{Eskatologie}

Sonder om te wil veralgemeen, moet tog opgemerk word dat daar by sommige feministe 'n sterk tendens van horisontalisme merkbaar is, so asof die nuwe ryk van God logies en outomaties uit ons menslike aktiwiteite voortvloei. Daar is maw ' $n$ gebrek aan beklemtoning van die eskatologiese voorbehoud (die laaste oordeel). Al ons menslike maatskappykritiek en maatskappyverandering bring nie outomaties die koninkryk van God nie - waarmee natuurlik nie gesê is dat ons roeping vir 'n regverdige samelewing maar rustig nagelaat kan word nie.

\section{Samevatting}

Soos duidelik uit bostaande uiteensetting blyk, raak die FT inder- 
daad die ganse teologiese veld. Uit reaksie teen 'n paternalistiese teologie, kerk, Skrif en God kom die wekroep van feministiese omduiding, van feministiese bevryding en van 'n nuwe wêreld waarin man en vrou volkome gelyk is.

\section{EVALUERING}

Wanneer ons hier enkele bykomende en samevattende waarderings uitspreek, moet veral teen twee gevare gewaak word. Die eerste is die van generalisasie waar alle feministiese teoloë oor een kam geskeer en onder een kombers toegemaak word. Ons moet duidelik onderskei tussen diegene wat Bybels-teologies wil dink en diegene wat meer ideologies, georiënteerd is, anders raak ons kritiek goedkoop.

'n Tweede gevaar is die van simplisme, waardeur ons die stand. punte van feministe simplisties voorstel en maak asof hier teologies niks aan die orde is nie.

\subsection{Algemeen}

Dit moet sonder meer waardeer word dat die FT, in sy beste vorm, vanuit die evangelie aandag vra vir die plek en taak van die vrou in die kerk en samelewing. Met die strewe na humanisering hoef as sodanig nie fout gevind te word nie. Uit die geskiedenis blyk ook duidelik hoedat telkemale, ook in die teologie, die situasie van die underdogs aan die orde gestel is: slawe, handearbeiders, swartmense, vroue, swartvroue ens.

Wat die posisie van die vrou betref, is daar in die verlede nie baie vleiend geoorieel nie. Ons kan hier bv. aan die volgende Rabbynse spreuke dink: Moenie lank met 'n vrou praat nie, veral nic in die openbaar nie, selfs nie met jou eie vrou nie; 'n vrou mag nie as getuie optree, kinders onderrig of aan tafel bid nie. Rabbi Jehuda $(150 \mathrm{nC})$ het geleer dat elke Joodse man God daagiks moet prys en sê: Geprese is $U$ dat $U$ my nie as 'n heiden geskape het nie, en nie as 'n vrou nie, en nie as 'n slaaf nie! Die filosoof Nietzsche het gesê die vrou is die tweede misgreep van God.

Mens dink in hierdie verband ook aan die goedkoop egskei:lingsgronde wat in die tyd van Jesus gegeld het en waar die vrou feitlik geheel en al aan die willekeur van die man uitgelewer was: Rabbi Hillel het egskeiding voorgestaan wanneer die vrou die kos laat verbrand het en Rabbi Akiba wanneer 'n man 'n mooier vrou gevind het!

Ook in die kerkgeskiedenis is nie te mild oor haar geoordeel nie. Selfs groot kerkvaders, soos Augustinus, Luther en Calvyn, het in bepaalde opsigte 'n negatiewe kyk op haar gehad.

Oor die algemeen is gereformeerde kerke traag om die vrou tot bepaalde kerkdienste toe te laat. Die sinode van die GKSA het bv. in 1920 daarteen besluit dat vrouelidmate in die kerk en politiek mag stem - hoewel studiedeputate sedert 1979 weer aandag gee aan die roeping van die vrou in die kerk. Voortdurende besinning is inderdaad nodig. 
Negatiewe kritiek is nie moeilik nie, veral nie wat die sg radikale feministe betref nie. Die gedagte kan nie onderdruk word nie dat sommige feministe krities is daaroor dat die Here God die mens onderskeidend as man en vrou geskape het. Die FT oorspan sy standpunt as nie net alle superioriteit nie maar ook alle prioriteit as sondig afgewys word. Die Skrif word deur vele ook baie eklekties hanteer en in sommige gevalle selfs van sy openbaringskarakter beroof. Die gevaar van eensydigheid, moontlik as reaksie teen 'n piëtistiese teologie, is voortdurend sigbaar. Gelukkig word hierdie gevaar ook deur sommige herken: "Here we call attention to the tendency to identify without qualification the suffering of a particular group with righteousness and redemption" $\left({ }^{16}\right)$. Dit is waar dat die Here God Hom in besondere mate oor die ontregte ontferm, maar dit is nie waar nie dat God outomaties aan hulle kant is en dat hulle, sonder geloof in Jesus Christus om die ware verlossing kan ervaar. God is nie outomaties aan die kant van die vrou en teen alle mans nie, netsoos wat Hy nie outomaties vír alle swartmense is en téén alle witmense nie. God roep sy kinders uit álle soorte mense en die geloof in Christus - en natuurlik die konsekwensies wat daaruit. voortvloei - is die waarmerk hiervan. Wie enige ander kenmerk, bv. kleur of ras of sosiale status, hier sou invoer, tas die evangelie in sy hartaar aan. Daar is net een Naam waardeur iemand gered kan word (Hd $4: 12$; of Jh $14: 6 \mathrm{~b}$ ).

Menslike sunergisme is hierby - by die verlossing - ook volkome uitgesluit anders is die redding nie meer uit vrye genade nie maar uit goeie werke (Ef $2: 8-9$, Gl 5:4). Vandaar dat die volgende - miskien onbedagsame - formulering baie gevaarlik is: "salvation from corporate evil, therefore, requires participation in those political processes which seek to destroy injustice and misery" (17). Weliswaar praat die Skrif ook van "medewerkers van God" (sunergoi) (1 Kor 3:9), maar dan word dit van verlostes gesê en wel binne die raamwerk van die kerk - en so binne die raamwerk van die koninkryk. Selfs in so 'n pregnante gedeelte soos Flp 2:1213 bly die aksent val op dit wat Gód doen. As iemand nou sou meen dat hierdie leer - van God se vrye genade - sorgelose mense maak, dan het hy dit volkome misverstaan. Daar is niks wat meer dinamiek in die lewe losmaak as om in Christus te glo nie (HK $24: 64$ ). Maar werk in die koninkryk en werk vir 'n regverdige samelewing is iets anders as om jouself deur middel van sosiale hervorming te probeer red. Ons moet hier duidelik onderskei tussen die evangethe en die sosiale implikasies wat die evangelie met hom meebring.

\subsection{Vrou en kerk}

Ons het daarop gewys dat die F T besondere aandag vra vir die plek van die vrou in dic kerk en wel sodanig dat sy by alle aspekte van die kerklike lewe en werk ten volle betrek moet word. Dit is wel waar dat ons reeds in die Skrif met besondere vroue te doen kry, soos bv. Hagar (Egiptiese slavin van Sarai), Lea (die onderdrukte!), Sifra en Pua (die Egiptiese vroedvroue), Debora (rigteres), Jael 
(wat Sisera gedood het), Attalia (koningin), Hulda (profetes), Anna (profetes), Maria (moeder van Jesus), Maria Magdalena ens, maar vir die $F \mathrm{~T}$ is hierdie uitsonderinge te min. Die vrou moet kerklik ten volle geëmansipeer word.

Wat antwoord ons hierop kortliks?

Reformatoriese kerke wat oor hierdie onderwerp besin het, het vanselfsprekend met die Skrif en met eksegese begin. Wat die eksegese egter in 'n besondere mate bemoeilik, is die feit dat daar in die F T oënskynlik twee denklyne terug te vind is. Volgens dic een lyn skyn dit of daar aan die vrou 'n ondergeskikte posisie toegeskryf word: 1 Kor. $14: 34$, Ef. $5: 22-24$, Kol. $3: 18,1$ Tm. $2: 11$, Tt. $2: 5,1$ Pt. $3: 5$. Die ander lyn skyn meer te dui op 'n volwaardige posisie: Lk. $2: 36$, Hd. $2: 18,18: 26,21: 9$, Rm. 16, 1 Kor. $11: 5$, Gl. $3: 28,1 \mathrm{Tm} .5: 10$, Tt. $2: 3$. Dit is baie verleidelik om slegs aan een van hierdie reeks gegewens vas te hou en daaruit dan 'n finale antwoord te trek. Dit is nie oordrewe nie om te sê dat 1 Kor. 14:34 (en $1 \mathrm{Tm} .2: 12$ ) in hierdie verband altyd sterk gefigureer het om die vrouens swygsaam te hou, maar die vraag kan gestel word of hierdie teks altyd in sy konteks (1 Kor. 12-14) verstaan is. Praat Paulus hier van die getroude of ongetroude vrou? Handel hy oor babbel - wat ontstigtelik is - of oor lering? Watter verband is daar met die profetesse van 1 Kor. $11: 5$ ?

In die optrede van Christus neem vrouens 'n besondere plek in. Opvallend is ook sy onkonvensionele optrede en dat haas elke ontmoeting met ' $n$ vrou in botsing was met die bestaande rabbynse sede. Hy praat in die openbaar met 'n Samaritaanse vrou (Jh. 4); Hy raak ' $n$ bloedvloeiende vrou aan (Mt. 9:20); Hy laat vroue Hom navolg (Lk. 8:1-3, Mt. $21: 31 \mathrm{v}$ ); Hy behandel 'n owerspeligc vrou pastoraal (Jh. 8:1-11); Hy laat toe dat 'n verdagte vrou Hom salf (Lk. $7: 36 \mathrm{v}$ ); Hy gaan spontaan met vrouens om, bv. met Marta en Maria (Lk. 10:38-42). Daar is by Hom geen spoor van diskriminasie teen die vrou te vind nie. Geen wonder ook dat vrouens die eerstc verkondigers van sy opstanding word nie (Mt. 28:10, Jh 20:17).

In die NT word van die mooiste dinge ook van vroue gesê: hulle is mede-ontvangers van die Heilige Gees (Hd. 2:18); medelidmaat van die gemeente (Hd. $1: 14$ ); mede-ontvanger van die heilige doop (Hd. 16:15) en mede-deelnemer aan die maaltyd van die Here (Hd. 2:42, 46); mede-arbeider in die gemeente (Rm. 16); mede-ontvanger van die geestesgawes (1 Kor. 12); mede-erfgenaam van die genade (1 Pt. 2:7). Dit maak nie meer saak of iemand man of vrou is nie: in Christus Jesus is hulle éen (Gl. $3: 28$ ).

Op talle plekke in die NT tref ons die aktiewe vrou aan: Dorkas (Hd. 9:36v); Prissilla, die medewerker van Paulus, moet broeder (ds?) Apollos nader onderrig (Hd. $18:: 26 \mathrm{vgl}$. Rm. 16:3); in Lidia se huis word eredienste gehou (Hd. 16:40); Filippus se vier ongetroude dogters profeteer (Hd. 21:9; vgl. 1 Kor. 11:5); Febe is 'n dienares (diakones?) in die gemeente van Kengreë (Rm. 16:1); Maria, die arbeider in die gemeente (Rm. 16:6); so ook Junias (Rm. 16:7), Trifena en Trifosa (Rm. $16: 12$ ) en Julia (Rm. 16:15); Euo- 
dia en Sintige Flp. 4:2-3); Nimfa (Kol. $4: 15$ ); dienende weduwees (1 Tm. $5: 10$ ).

Waarop dui al hierdie gegewens en wat is die strekking daarvan? Sommige kerkgroeperinge het oa. hieruit afgelei dat daar geen deurslaggewende Skriftuurlike argumente teen 'n vrou in die besondere dienste aangevoer kan word nie. So bv. het die Ndl. Herv. Kerk in 1958 ten gunste van die vrou in die dienste besluit en in 1970 is die eerste vrouepredikant in die GKN bevestig. In SA het die NHKA sedert 1973 diakonesse en sedert 1979 vrouepredikante toegelaat. Sedert 1982 het die NGK diakonesse toegelaat. Die GKSA het in 1979 studiedeputate aangewys oor wie se aanbevelings nog later besluit sal word.

Samevattend kan mi. gestel word dat daar geen deurslaggewende Skriftuurlike en kerkregtelike argumente teen stembevoegdheid van die vrou aangevoer kan word nie. Ons het in die kerk van die Here immers nie met 'n demokrasie nie maar met 'n Christokrasie te doen. Christus delegeer nie sy gesag aan mense nie maar Hy sonder mense af om sy gesag te bedien.

Verder dui die mees relevante Skrifgegewens (Rm. 16:1-2, 1 Tm. 1:8-13, 1 Tm. 5:1-10) asook die Skriftuurlike geheelbeeld van die karakter en eieaard van die diakendiens daarop dat vrouens ook hierin mag dien.

Wat die ouderling- en predikantsdienste betref, behoort die studie en besinning voort te gaan, veral in die lig van die skopus en totaliteit van die Skrifboodskap.

\section{SLOT}

Die $F$ T het ' $n$ aantal besonder dringende vrae voor die teologiese deur kom lê. Ons sal daarop alleen vanuit die evangelie 'n waardige antwoord kan gee Daar is trouens niks ter wêreld wat aan vroue groter en beter vryheid kan skenk as die evangelie van Christus Jesus. Daar is niks wat 'n vrou meer méns kan laat wees as die goeie boodskap nie. Binne watter ander ruimte, as die koninkryk van God, kan 'n vrou haar talente en gawes beter en omvattender uitleef? Dit is alleen die bnodskap van God se nuwe ryk wat die volle lewe vir vroue ontsluit.

J. H. van Wyk.

\section{VOETNOTAS}

1. Letty Russell 1974. 20.

2. Jacquelyn Grant, in Wilmore en Cone 19823, 419.

3. Pauli Murray, in Wilmore en Cone 19823, 398.

4. Mary Burke, in Torres en Fabella 1976, 200.

5. Vgl. Russell 1974, 81.

6. Jacquelyn Grant, in Wilmore en Cone 19823, 420. 
7. Idem 422.

8. Idem 427.

9. Grant, in Wilmore en Cone $1982^{3}, 430$.

10. Vgl. M. C. Faque 1983, 152 V.

11. Vgl. Catharina Halkes 19842, $9-10$.

Sy wys op vier modelle en kies self vir die laaste: paternalistiese model, polariteits (of komplementariteits) model, emansipasie (of egalitere) model en tran;formatiewe model.

12. Velema, W. H. Maart 1985 . De daders leven ook binnen de kerk. Koers (Ndl). $16-18$.

13. Ruetrer 1972, 8; vgl. Halkes 19842, $12-13$.

14. Grant, in Wilmorc en Cone 1982', 423.

15. Idem 431.

16. Murray, in Wilmore en Cone 19823, 413.

17. Idem $400-401$.

\section{BIBLIOGRAFIE}

Anderson, G. \& Stransky, T (Ed). 1979. Liberation theologies. New York: Paulist Press.

Berry, W. W. 1978. Images of $\sin$ and salvation in feminist theology. A Th $R$ $60,25-54$.

Bianchi, El \& Ruether, R. R. 1967. From Machismo to Mutuality. New York: Paulist Press.

Boelema, J. 7 Jan. 1933-28 Okt. 1983. Sewe artikels oor Feminisme. Koers (Reformatorisch opiniblad).

Bolkestein M. H. Bolkestein- van Binsbergen, H. J. 1982 . Vrouw zijn in het licht van het evangelie: een bundel feministisch-theologische studies. Baarn: Ten Have.

Caprio, Betsy. 1982. The Woman Sealed in the Tower: A Psychological Approach to Feminine Spirituality. New York: Paulist Press.

Clark, E. \& Richardson, H. W (Ed). 1977. Women and Religion a feminist sourcebook of Christian thought. New York: Harper.

Collins, Sheila D. 1974. A different Heaven and Earth. Valley Forge: Judson Press.

* Daly, Mary. 1975. The Church and the Second Sex: with a New Feminist Post-Christian Introduction by the Author. New York: Harper Colophon Books.

Daly, Mary. 1978: Gyn-ecology. the metaethics of radical feminism. Boston: Beacon.

De Beauvoir, Simone. 1972. The Second Sex. London: Jonathan Cape.

Doely, S. B. (Ed). 1970. Women's liberation and the church: the new demand for freedom in the life of the Christian church. New York: Association.

Edwards, F. 1981. The doctrine of God and the feminine principle. J TSA $37: 23-37$. 
Evans, J. H. 1981. Black theology and black feminism. JRT $38,43-53$.

Fiorenza, E. S. 1975. Feminist theology as a critical theology of liberation. Theological Studies $36: 605-626$.

Fiorenza. E. S. 1982. Feminist theology and New Testament interpretation. JSOT $22: 32-46$.

Ferm, D. W. 1981. Feminist theology in America. SJ Th $34: 157-178$.

- Daly, Mary. 1973. Beyond God the Father: Toward a Philosophy of Women's Liberation. Boston: Beacon Press.

Fiorenza, Elizabeth S. 1983. In Memory of Her: A Feminist Theological Reconstruction of Christian Origins. New York: Crossroad.

Halkes, Cartharina - J. M. Buddingh D. (red). 1977. Als vrouwen aan het Woord komen: aspecten van de feministische theologie. Kampen.

Halkes, Catharina J. M. 1880. Met Mirjam is het begonnen: opstandige vrouwen op zoek naar hun geloof. Kampen.

Halkes, Catharina J. M. (red). 1981. Op water en brood. Baarn.

Halkes, C. J. M. 19842. Vrouwen - mannen - mensen (Rede uitgesproken bij de aanvaarding van het ambt van bijzonder hoogleraar in feminisme en christendom aan de katholieke universiteit in Nijmegen op 6 April 1984). Baarn Ambo.

Halkes. C. J. M. 198 . Zoekend naar wat verloren ging: Enkele aanzetten voor een feministische theologie.

Katoppo, Marianne. 1980. Bewogen en vrij: een vrouwelijke theologische stem uit Aził. Kampen.

Litfin, A. D. 1979. Evangelical feminism: Why traditionalists reject it. B S 136: $258-271$.

Mc Fague, Sallie. 1982. Metaphorical Theology: Models of God in Religions Language. London: SCM Press (veral hfst 5).

Moltmann-Wendel, El zabeth. 1978. Vrijheid, gelijkheid, zusterschap: emancipatie van de vrouw in kerk en maatschappij. Baarn

Idem. 1982. Bij Jezus tellen vrouwen mee: evangelieverhalen doorbreken gevestigde patronen. Baarn.

Oduyoyc, M. A. 1980. Women and the church in Africa: perspective; from the present. Volces from the third world $3(2)$ : 17-24.

Ruether, Rosemary Radford. 1972. Liberation Theology. New York: Paulist Press.

Ruether, Rosemary. 1975. New Woman/New Earth: Sexist Ideologies and Human Liberation. New York: Seabury Press.

Ruether, R. R. 1976. Mary: the feminine face of the church. Philadelphia: Westminster.

Ruether, Rosemary $R$ 1083. Sexism and God-Talk: Toward a Feminist, Theology. Boston: Beacon.

Runia, K. 14 Des. 1983. Een nieuwe feministische vertaling van de bijbel. Centraal Weekblad.

Russell. Letty, M. 1978. Het bevrijdende Woord Baarn.

Russel, Letty M. 1974. Human Liberation in a Feminist Perspective: A Theology. Philadelphia: Westminster Press.

Russell, L. M. 1976. The liberation word a guide to nonsexist interpretation of the Bible. Philadephia: Westminster. 
Torres, Segio \& Fabella, Virginia (Ed). 1976. Theology in the Americas. New York: Orbis.

W. S. Vorster ed. 1984. Sexism and Feminism in Theological Perspective. Unisa-seminaar, 5-6 Sept. 1984.

Visser't Hooft. 1982. The fatherhood of God in an age of emancipation. Geneva: W. C. C.

Wilmore, G. S. \& Cone J. H. 19823. Black Theology: A Documentary History 1966-1979. New York: Orbis Books (Part V).

\section{VERDER}

- Conn, Harvie M. Spring 1984. Evangelical Feminism: Some Bibliographical Reflections on the Contemporary State of the "Union". The Westminster Theological Journal, XLVI (1): $104-124$.

- Imbers. Annie en Jonker, Ineke. 1985.

Godsdienst en incest. Amersfoort: De Horstink.

- Mangan, Céline. 1984. Can we still call God "Father"?

Wilmington: Michael Glazier.

- Mollenkott, Virginia Ramey. 1983.

The Divine Feminine: The Biblical Imagenary of God as Female.

New York: Crossroad.

- Mottu, Henry. April - Junie 1984. Der Feminismus und die Verănderung der Rolle des Mannes. Zeitschrift fur Evangelische Ethik, 28(2): 213 222.

- Oxford - Carpentrr, Rebecca. Apr. 1984.

Gender and the Trinity. Theology Today, XLI (1): $7-25$. 